\title{
Contribution to the Improvement of the Earthing Resistance of Electrical Installations: Case of Tropical Zones Lands
}

\author{
Mathurin Gogom*, Rodolphe Gomba, Desire Lilonga-Boyenga \\ Polytechnical Superior National School Ecole Nationale Superieure Polytechnique, Marien Ngouabi University, Brazzaville, Congo \\ Email address: \\ mathuringogom@gmail.com (M. Gogom), gombarodolphe@gmail.com (R. Gomba), lilongadesire@yahoo.fr (D. Lilonga-Boyenga) \\ ${ }^{*}$ Corresponding author
}

To cite this article:

Mathurin Gogom, Rodolphe Gomba, Desire Lilonga-Boyenga. Contribution to the Improvement of the Earthing Resistance of Electrical Installations: Case of Tropical Zones Lands. Science Journal of Energy Engineering. Vol. 8, No. 1, 2020, pp. 1-5.

doi: $10.11648 /$ j.sjee.20200801.11

Received: January 30, 2020; Accepted: February 18, 2020; Published: February 26, 2020

\begin{abstract}
Optimizing the earthing resistance is still a challenge with regard to the damage that continues to occur in electrical installations due to the poor earth network. The research carried out to date does not take into account the diversity of soils often characterized by its intrinsic value of resistivity. The generalization of grounding techniques gives in some places high resistances of the ground circuit. In fact, much remains to be done in terms of optimizing the resistance of the earth circuit. This very exciting problem concerns not only industrial frequency circuits, but also high frequency circuits often meet in telecommunications. In this area, account must be taken of the reactance of the grounded rods, and therefore the impedance, which is often negligible at low frequencies, thus in this paper we present a comparative study of the variation of the earth resistance of the different types of soil depending on the length of the earth stake on the one hand, and on the diameter of the earth hole on the other hand. The interest of this work is to find an approach which would be allowed to realize an earth network having an optimal resistance whatever the type of soil.
\end{abstract}

Keywords: Earth Resistance, Ground Stake Length, Soil Types, Earth Circuit, Earth Hole Diameter

\section{Introduction}

Manufacturers, operators and users of electrical networks are constantly in contact with electrical equipment of all kinds, from production, processing, transport and distribution devices to end consumers. However, the carcasses of these equipments can accidentally find themselves under associated voltages and currents that exceed what the human body can tolerate. Similarly, shock waves of atmospheric origin or due to maneuvers permanently constitute a danger for electrical equipments. Thus, special precautions must be taken so that they can be touched without danger and these shock waves do not have to damage these equipments.

This is grounding, often called earth, which is the set of means used to connect a part of the electrical installation to earth which may accidentally be energized. It is a way of securing people and electrical installations which must operate harmoniously, whether at high, medium or low voltage. An earthing system consists of a rod buried in the ground and connected by a conductor to the neutral of the circuit to which differents equipments are connected.

In any low, medium or high voltage electrical installation, the metal masses of the receivers are generally interconnected. The interconnection can be total or carried out by groups of receivers. Each interconnected group is connected to an earth connection of a given resistance. It is also possible that one or more masse to be individually earthed.

Studies on the choice of techniques for earthing the neutral of low, medium or high voltage networks have long been a controversial and passionate subject, given the impossibility of finding a unique compromise for the different types of networks. Today's experience allows us to make a relevant choice based on the specific constraints of each network. In this perspective, the different types of neutral ground connection are compared, which are distinguished by their 
method of connecting the neutral point and their operating technique [1-3, 8-9]:

1. The neutral directly earthed;

2. The isolated neutral, or strongly impedant;

3. The neutral earthed via a reactance;

4. The neutral earthed via a reactance (PETERSEN coil).

Also, the problem of optimizing the grounding resistance has been the subject of several studies which have resulted in the reduction of the ground resistance by increasing either the length of the 'electrode, either the distance between electrodes, or the number of electrodes, or the diameter of the electrode, or using the material of low resistivity [3-5].

Despite these results, there is another challenge notably that of soil resistivity which depends on the type of soil for which the developed models do not take into account. Thus, it is clear that by considering the same model one obtains different earth resistance values, for which, some are very high causing until now inconvenience in electrical installations.

With regard to this problem, this study proposes to identify the soils by taking into account their resistivity in order to obtain grounding models adapted to the different types of soil with optimal resistances which would guarantee the rapid flow of the faults currents due to various causes (lightning strikes, unpredictable contacts between active and non-active parts and others).

It will examine the behavior of earthing at industrial frequency and steady state. In addition, we will use in the simulations the average value of the resistivity of each type of soil, which is the case in tropical regions.

\section{Theoretical Approach}

The soil is a heterogeneous assembly of particles or crystals with very variable properties: dimensions, shapes, physicochemical properties, etc. There are several types of soil among which we can cite: marshy soils, silt, humus,
Jurassic marl, clay, wet peat, stony, cracked limestone, compact limestone, soft limestone, mica schists, granite and sandstone, siliceous, shale, etc.

Whatever the intended use of a soil, it is important to know its nature, its composition, the distribution of grains of different sizes that compose it and the different seasons.

The composition of the soil, its moisture content and its temperature have an impact on the resistivity of the soil. The soil is rarely homogeneous and the resistivity of the soil varies according to the geographic region and to the different depths of it. The moisture content varies with the seasons and the nature of the sub-strata of the land and the depth of the permanent water table [3-6].

\subsection{Electrical Characteristics of Soils}

Soil resistivity is the specific resistance of the soil. It depends on several factors that influence the formation of electrolytes. Soil resistivity is a variable quantity and the only way to know it precisely is to measure it. It varies according to several factors, in particular: the nature of the soils, the chemical composition of the salts, the concentration of the dissolved salts in the water contained, the temperature, the grain sizes, the porosity, the percentage of water contained in the soil, the percentage of acid and bases. At constant temperature, the resistivity of the ground is comparable to the resistivity of a metallic conductor of length $\mathrm{L}$ and of given section s. It depends on its nature and is expressed in ohmmeter $(\Omega . \mathrm{m})$. It is given by the following classic formula:

$$
\rho=R \frac{S}{l}
$$

Where $\rho$, is the material resistivity $(\Omega . \mathrm{m}) ; R$, is the measured resistance $(\Omega) ; s$, is the conductor section $\left(\mathrm{m}^{2}\right)$; $l$, is the conductor length $(\mathrm{m})$.

Table 1 below gives an indication of the resistivities of the different types of soil [4-5-8].

Table 1. Average resistivities of the different types of soil.

\begin{tabular}{llll}
\hline Soil types & Resistivity $(\mathbf{\Omega m})$ & Soil types & Resistivity $(\mathbf{\Omega m})$ \\
\hline Swampy land & From some unit to 30 & Cracked limestones & 500 to 1000 \\
Silt & 20 to 100 & Shales & 50 to 300 \\
Humus & 100 to 150 & Soft limestone & 100 to 500 \\
Wet peat & 5 à 100 & Compact limestones & 1000 to 5000 \\
Plastic clay & 50 & Bare stony ground & 1500 to 3000 \\
Marls and clays compact & 100 to 200 & Stony ground covered with grass & 300 to 500 \\
Clay sand & 50 to 500 & micaschists & 800 \\
Silica sand & 200 to 3000 & Granites and Sandstone & 100 to 10000 \\
\hline
\end{tabular}

As this table 1 indicates, siliceous soils, cracked limestones, compact limestones, bare stony and granites and sandstones. These values take into account the state of the soil, wet or dry.

\subsection{Calculation of Earthing Resistances}

There are several analytical methods for assessing the grounding resistance of different electrode configurations. The relationships given in the following paragraphs assume a uniform resistivity of the soil (homogeneous soil). In practice, to take into account the heterogeneity of the soil, we often assume two layers of different resistivities. The different configurations depend on the form of earth connection [3].

All the configurations relate to an equivalent hemisphere which would give a value of earth resistance considered. An example of a ground stake of cylindrical and vertical shape investigated by SEMAN Georges [5] is given in figure 1 . 


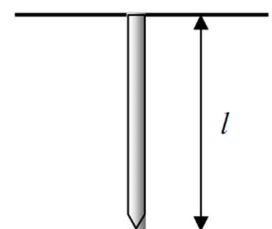

Figure 1. Vertical cylindrical electrode.

To optimize the resistance of the earth circuit, four relationships have been developed in the literature, the fourth of which takes into account the addition of material with low resistivity (carbon or others) [3-4]. Indeed, the addition of low resistivity material significantly reduces the earth resistance. These relations giving the earth resistance are respectively:

Rudenberg approximation

$$
R=\frac{\rho}{2 \pi l}\left(\ln \frac{4 l}{d}\right)
$$

where $\rho$, is the soil restivity $(\Omega . m) ; l$, is the electrode length $(\mathrm{m})$; $\mathrm{d}$, is the electrode diameter $(\mathrm{m})$.

Dwight-Sunde approximation

$$
R=\frac{\rho}{2 \pi l}\left(\ln \frac{8 l}{d}-1\right)
$$

Liew-Darveniza approximation

$$
R=\frac{\rho}{2 \pi l}\left(\ln \frac{r+l}{r}\right)
$$

where $r$, is the electrode radius.

When we have several earth electrodes, it is important to know the equivalent radius of the hemisphere which would have the same resistance as an earth electrode. The equivalent radius is given by the relation:

$$
r_{e q}=\frac{\rho}{2 \pi R_{\text {stake }}}
$$

$\mathrm{R}_{\text {stake, }}$ is the stake resistance.

Fagan-Lee approximation

In the case where the material with low resistivity is used, the grounding resistance may decrease by acting on the natural resistivity of the ground surrounding the electrodes. For this, a pit is dug in the immediate vicinity of the conductor and then the materials of low resistivity are fled. For different soils, it is enough to make a hole about two meters in diameter and three meters deep. In this hole several earth connections can be used, in order to further lower the earth resistance. To backfill the hole, materials like charcoal, humus, salt are used and the hole is then sprinkled with a huge amount of water. The earth resistance is given by the following relation [3-4-8-10]:

$$
R=\frac{1}{2 \pi l}\left\{\rho_{m} \ln \left(\frac{r_{m}}{r}\right)+\rho\left[\ln \left(\frac{4 l}{r_{m}}\right)-1\right]\right\}
$$

where $l$, is the stake length; $\rho$, is the soil resistivity; $\rho_{m}$, is the resistivity of the material around the electrode; $r$, is the electrode radius; $r_{m}$, is the radius of the material around the electrode.

This technique of surrounding the earth electrode with a layer of low-resistance material is shown in Figure 2 below.

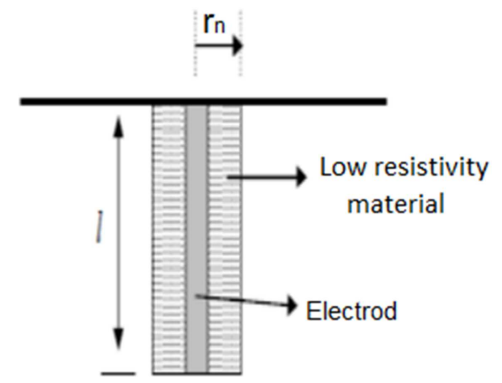

Figure 2. Addition of low resistivity material around the electrode.

Indeed, one can vary the resistance of earth connection according to the length of the stake or the diameter of the earth hole to obtain an optimal value.

\section{Results and Discussion}

We used MATLAB software to simulate the earth resistance from the relation [6]. Knowing the average values of the resistivity of the soil considered and of the material of low resistivity, the radiuses of the hole and the stake, we vary the length of the stake on the one hand; similarly with the knowledge of the average values of the resistivity of the soil considered and of the material of low resistivity, the radius of the stake, we vary the diameter of the hole on the one hand. For our simulations, we have targeted soft limestone, plastic clay, fissile limestone, silica sand, stony soil, compact limestone and clay sand often encountered in tropical areas.

In the implementation of the simulations, we were mainly interested in the influence on the earthing resistance of the length of the ground stake and the radius of the earthing hole.

\subsection{Influence of the Stake Length on the Earth Resistance}

The resistance variation of different types of soil depending on the length of the earth stake is illustrated in Figure 3 below. The average resistivity of the soils examined and the radius of the hole are respectively the sum of the minimum and maximum values divided by two, and of 0.5 m.

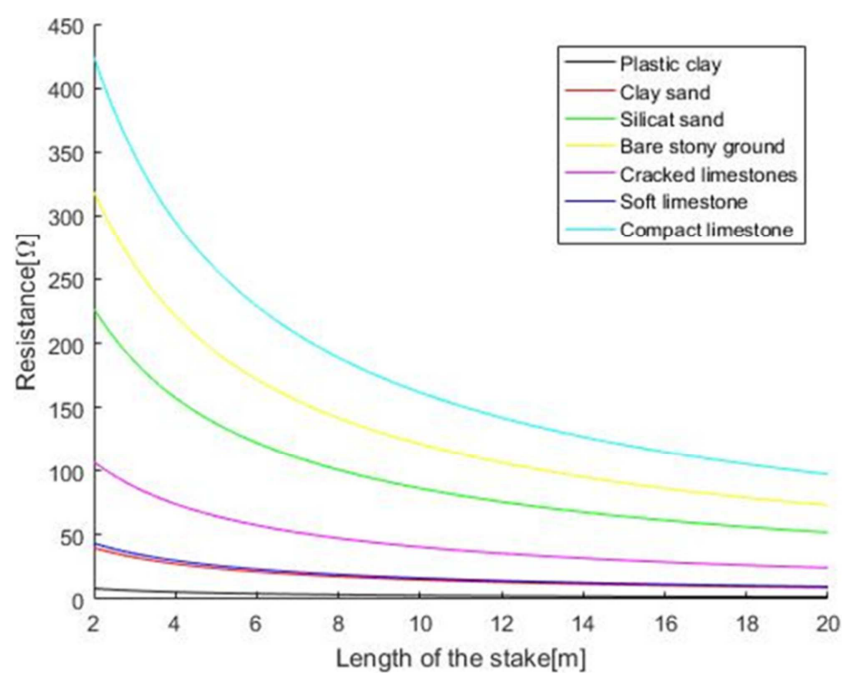

Figure 3. Resistance variations depending on the length of the stake. 
This figure 3 shows that the results obtained at the end of the simulations are better for soils of the types: plastic clay, clay sand and soft limestone. However, certain soils require, apart from the application of the low resistance material, the use of several earth stakes defined according to Table 2 below.

Table 2. Variations in earth resistance as a function of the number of stakes.

\begin{tabular}{lllll}
\hline $\mathbf{N}^{\circ}$ & Soil types & Resistance at $\mathbf{5}$ m depth $(\boldsymbol{\Omega})$ & Number of stake & Improved resistance $(\boldsymbol{\Omega})$ \\
\hline 1 & Cracky limestone & 64.7 & 3 & 21.6 \\
2 & Silica sand & 137.4558 & 5 & 26.89 \\
3 & Stony ground & 193.0891 & 8 & 24.136 \\
4 & Compact limestone & 257.2813 & 10 & 25.728 \\
\hline
\end{tabular}

We note that the number of stakes in some cases is high requiring a significant investment. Thus, to dig more to minimize the number of electrodes, a technical-economic study is essential.

\subsection{Influence of the Radius of the Earth Hole on the Earth Resistance}

The resistance variation of different types of soil depending on the diameter of the hole is illustrated in Figure 4 below when the length of the stake is $2 \mathrm{~m}$.

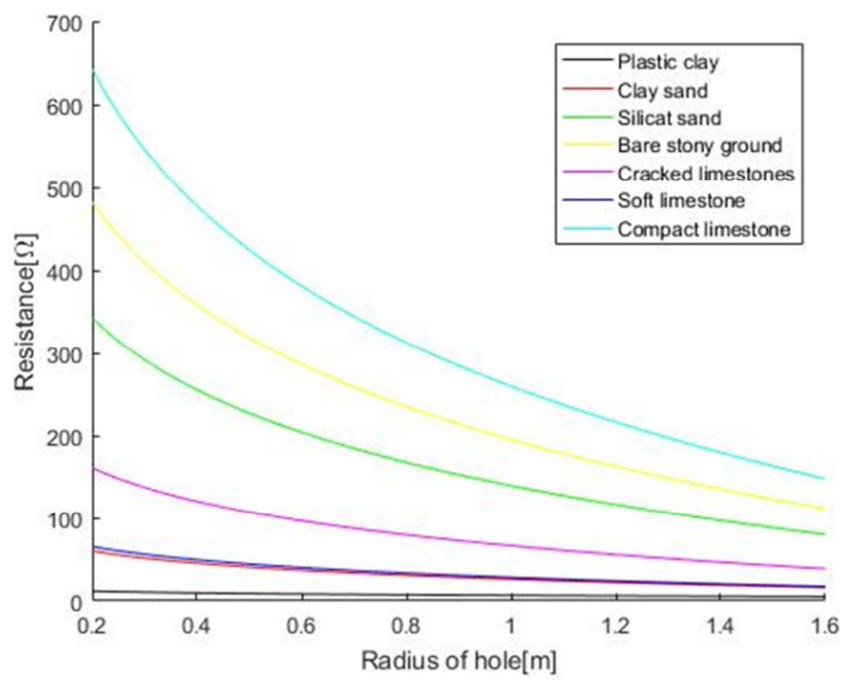

Figure 4. Earth resistance variations depending on the hole.

The simulations made here led to the best results for soils of the following types: plastic clay, clay sand, soft limestone and fissile limestone. However, some soils require, despite the application of the low resistance material, the use of several earth stakes defined according to Table 3 below.

Table 3. Earth resistance variations depending on the number of stakes.

\begin{tabular}{|c|c|c|c|c|}
\hline $\mathbf{N}^{\circ}$ & Soil types & $\begin{array}{l}\text { Resistance }(\Omega) \text { for } \\
\text { a radius of } 1.5 \mathrm{~m}\end{array}$ & $\begin{array}{l}\text { Number } \\
\text { of Stake }\end{array}$ & $\begin{array}{l}\text { Improved } \\
\text { resistance }(\Omega)\end{array}$ \\
\hline 1 & Silica sand & 87.9663 & 3 & 29.3321 \\
\hline 2 & Stony soil & 122.83 & 4 & 30.7075 \\
\hline 3 & $\begin{array}{l}\text { Compact } \\
\text { limestone }\end{array}$ & 163.055 & 6 & 27.1758 \\
\hline
\end{tabular}

Table 3 above shows the earth circuit resistances which are still very high when the radius of the earth hole is $1.5 \mathrm{~m}$, however they can be improved by increasing the number of earth stakes.

\section{Conclusion}

As part of this study, we analyzed the influence on the earth circuit resistance of the stake length and the earth hole. The results obtained show that:

1. the earth resistance variations depending on the radius of the earth hole provide better optimization compared to the earth circuit resistance variations depending on the earth length electrode;

2. In some cases, where the earth circuit resistance no longer varies enough, regardless of the increase of the electrode length or the earth radius, several electrodes can be used in parallel.

In sum, the results obtained at the end of this study constitute a contribution for the electricity companies. However, a good study of comparison of resistivity of charcoal of different species must be carried out.

\section{References}

[1] Bernard Lacroix et Roland Calvas. Schémas des liaisons à la terre dans le monde et évolutions. Cahier technique $n^{\circ} 173$ édition septembre 1998 .

[2] Bernard Lacroix et Roland Calvas. Schémas des liaisons à la terre en BT (régimes du neutre). Cahier technique $n^{\circ} 172$ édition mai 2001

[3] Jean-Pierre NZURU NSEKERE. Contribution à l'analyse et à la réalisation des mises à la terre des installations électriques dans les régions tropicales. Thèse présentée en février 2009 à l'université de Liège.

[4] ZIDANE ZINE ABIDDINE. Modélisation et simulation des prises de terre dans les systèmes électriques. Mémoire de magister présentée le 13/5/2012 à l'université Ferhat AbbasSetiif.

[5] SEMAAN GEORGES. Évaluation de l'effet de la mer et du contrepoids sur le profil de la tension d'un système de mise à la terre d'une ligne de transport d'énergie à haute tension dans un sol résistif. Thèse présentée en septembre 2001 à l'École de Technologie Supérieure de l'Université de Québec.

[6] Arthur FLURY AG. Mise à la terre. Paratonnerre. Protection contre les surtensions. Edition 2017.

[7] François JULLIEN et Isabelle HERITIER. Le schéma IT (à neutre isolé) des liaisons à la terre en BT. Cahier technique $\mathrm{n}^{\circ}$ 178 édition décembre 1998. 
[8] Houndedako S, Aredjodoun J., Vianou A., Espanet Ch., Adedjouma S.. Choix de la configuration d'une prise de terre de type piquet pour une protection optimale. Revue du CAMES - Sciences Appliquées et de l'Ingénieur. Cames 2014 - Published Online 2014 http://publication.lecames.org/.

[9] N'bali Lanoy KONAN. Etudes des Avaries de Résistances de Mise à la Terre sur les Transformateurs HTB/HTA des Postes Sources de CÔTE D'IVOIRE. Mémoire de diplôme d'Ingénieur 2iE avec grade de Master présenté le 17 Janvier 2018 à l'Institut International d'Ingénierie de Ouagadougou 01 - BURKINA FASO.

[10] Tahar ROUIBAH. Contribution à la modélisation et à la simulation des prises de terre des installations électriques. Thèse présentée le 11/11/2015 Université Ferhat ABBESSITIF1.

[11] Gabriel Papaiz Garbini. Contribution au calcul des élévations de potentiel de sol en contexte ferroviaire. Thèse soutenue le 25/06/2015.

[12] Prof. J. L. Lilien. Analyse comparative des mises à la terre aux USA et dans divers pays d'Europe: influences sur les courants de contact. Cours année 2004 - 2005. Université de Liège.
[13] Hoang Vo Van HUY. Optimisation des techniques de mise à la terre des écrans des câbles à haute et très haute tensions. Thèse soutenue le 9 novembre 1999.

[14] Commission d'étude des questions relatives à la haute tension $\mathrm{CEH}$. Technique de mesure des mises à la terre des installations à haute tension, nouveaux procédés. Bulletin SEVNSE 23/95, P 31-39, 1995. Voltastrasse 9, 8044 Zurich.

[15] Xavier Legrand. Modélisation des systèmes de mise à la terre des lignes électriques soumises à des transitoires de foudres. Thèse de doctorat, l'école doctorale de Lyon, 2007.

[16] Commission Electrotechnique Internationale (CEI), 2002 CEI 60364-5-54: Installations électriques des bâtiments, choix et mise en œuvre des matériels électriques - Mises à la terre, conducteurs de protection et d'équipotentialité, 2ème édition 2002-06.

[17] Commission Electrotechnique Internationale (CEI), 2005 CEI 60479-1: Effets du courant sur l'homme et les animaux domestiques - Partie 1: Aspects généraux, Ed. 4, 2005.

[18] Werner, D. H. and R. J. Allard. The simultaneous interpolation of antenna radiation patterns in both the spatial and frequency domains using modelbased parameter estimation. IEEE trans. Antennas propagat., Vol. 48, No. 3, pp. 383-400, Mar 2000. 